\title{
RANCANG BANGUN SISTEM INFORMASI BERBASIS WEB PADA TEACHING FACTORY BAKERY SMK PUTRA ANDA BINJAI
}

\author{
Syaiful Bahri \\ Fakultas Sains dan Teknologi, Universitas Pembangunan Panca Budi \\ syaiful.bahri@dosen.pancabudi.ac.id
}

\begin{abstract}
ABSTRAK
Teaching Factory merupakan program pendidikan yang diterapkan di SMK. Teaching factory merupakan suatu metode pembelajaran yang diciptakan untuk media belajar siswa menghadapi dunia kerja yang nyata. SMK Putra Anda Binjai memiliki 1teaching factory bakery pada jurusan tata boga. Dalam hal ini teaching factory bakery belum memiliki sistem informasi yang bisa mempromosikan hasil produksi roti yang dibuat oleh siswa/i jurusan tata boga. Sistem informasi berbasis web merupakan salah satu teknologi informasi yang memudahkan dalam proses promosi di sosial media. Dengan menggunakan sistem informasi berbasis web, maka tim teaching factory bakery akan lebih mudah dalam mempromosikan roti yang mereka buat, sehingga mampu meningkatkan produksi penjualan. Dari hasil promosi menggunakan sistem informasi website, banyak orang mengetahui bahwa SMK Putra Anda memiliki teaching factory bakery sehingga banyak orang mulai memesan roti buatan siswa/i jurusan tata boga. Hal ini dikarenakan promosi yang tepat sasaran yaitu menggunakan sosial media yang merupakan satu kunci sukses dalam promosi.
\end{abstract}

\section{Kata kunci:Teaching Factory, Sistem Informasi, Website}

\section{ABSTRACT}

Teaching Factory is an educational program implemented at SMK. Teaching factory is a learning method created for student learning media to face the real world of work. SMK Putra Anda Binjai has 1 teaching factory bakery in the culinary department. In this case, the teaching factory bakery does not yet have an information system that can promote the production of bread made by students majoring in culinary. Web-based information systems are one of the information technologies that facilitate the promotion process on social media. By using a web-based information system, the bakery teaching factory team will find it easier to promote the bread they make, thereby increasing sales production. From the results of the promotion using the website information system, many people know that SMK Putra Anda has a teaching factory bakery so many people start ordering bread made by students majoring in culinary. This is because the promotion is right on target, namely using social media which is a key to success in promotion.

Keywords: Teaching Factory, Information System, Website 


\section{PENDAHULUAN}

Perkembangan teknologi yang semakin cepat membuat segala laporan pekerjaan juga harus dengan cepat. Selain dari itu mempromosikan barang atau jasa juga saat ini sudah sangat cepat dan seba digital. Website merupakan salah satu cara yang efektif dalam mempromosikan barang atau jasa yang kita buat. Dengan adanya website, segala informasi akan mudah diserap di sebarluaskan hanya dalam hitungan detik saja. SMK Putra anda merupakan salah satu sekolah di Kota Binjai yang memiliki unit usaha bakery melalui perkembangan jurusan tata boga. Dengan unit usaha yang dimiliki oleh jurusan tata boga saat ini masih jauh dari baik dalam mempromosikan hasil produksi bakery. Unit usaha bakery ini hanya mempromosikan bakery yang mereka buat di lingkungan sekolah. Hal ini tentu tidak akan mampu meningkatkan produktivitas hasil produksi bakery karena ruang lingkup yang sangat kecil.

Dengan adanya website yang bisa digunakan sebagai media promosi, nantinya semua hasil produksi akan di promosikan melalui website. Dengan adanya website bakery ini, maka sekolah dapat mempromosikan hasil produksi bakery lebih luas lagi, sehingga kedepannya secara perlahan mampu meningkatkan produktivitas produksi bakery pada SMK Putra Anda melalui jurusan tata boga.

\section{LANDASAN TEORI \\ 2.1 Definisi Sistem}

Sistem merupakan kelompok dan elemen yang digabungkan menjadi satu demi mencapai satu tujuan yang sama dan mencapai tujuan tertentu . Sistem juga merupakan suatu kesatuanyangterdiri dari komponen atau elemen yangdihubungkan mempermudah aliran informasi untuk mencapai tujuan tertentu sesuai yang diharapkan.Secara umum, sistem informasi terdiri dari 3 komponen, yaitu software, hardware dan brainware. Ketiga komponen ini saling berkaitan dalam proses kerja, maka ketiga komponen ini harus ada dalam 1 proses prosedur.

\subsection{Pengertian Informasi}

Informasi merupakan data yang sudah diolah yang bisa digunakan untuk proses pengambilan suatu keputusan dalam suatu penelitian (Sutabri, 2013). Sehingga sistem informasi dapat dikatakan sebagai data yang diolah atau dimanipulasi sesuai prosedur untuk keperluan penelitian yang berguna dan bermanfaat.

\subsection{Pengertian MySQL}

MySQL merupakan sistem database yang banyak digunakan untuk pengembangan aplikasi web. Alasannya mungkin karena gratis, pengelolaan datanya sederhana, memiliki tingkat keamanan yang bagus, mudah diperoleh, dan lain-lain. MySQL Merupakan database server yang paling sering digunakan dalam pemograman PHP (Buana, 2014). MySQL digunakan untuk menyimpan berbagai data dalam database dan data-datanya dapat dimanipulasi sesuai yang diperlukan. Manipulasi data tersebut yaitu berupa menambah, mengubah, dan menghapus data yang berada dalam database.

\subsection{Pengertian Database}

Database merupakan kumpulan dari banyak data yang saling berkaitan. Database memiliki relasi yang berbeda 
antar tabel dan memiliki fungsi yang berbeda-beda. Dengan adanya database, sistem informasi akan mudah dalam mengklasterkan data sesuai fungsinya. Dengan adanya database, sistem informasi dapat dengan mudah mencari informasi terkait apapun secara cepat. Database juga dapat dimodifikasi dengan mudah sesuai perubahan yang mungkin dapat terjadi suatu waktu dengan cepat dan mudah.

\subsection{Pengertian PHP}

Dalam pembuatan website, biasanya menggunakan bahasa pemrograman yaitu PHP. PHP merupakan salah satu bahasa pemrograman skrip yang dirancang untuk membangun aplikasi web. Ketika dipanggil dari web browser, program yang ditulis dengan $P H P$ akan di parsing di dalm web browser oleh interpreter PHP dan diterjemahkan ke dalam dokumen $H T M L$, yang selanjutnya akan ditampilkan kembali ke web browser. Karena pemrosesan program dilakukan di lingkungan web browser, PHP dikatakan sebagai bahasa sisi server. Oleh karena itu seperti yang telah dikemukakan sebelumnya, kode $P H P$ tidak akan terlihat pada saat user memilih perintah view source pada web browser yang mereka gunakan.

\subsection{Pengertian cPanel}

cPanel merupakan suatu kontrol panel yang berfungsi untuk mengelola pengaturan domain, hosting ataupun website. cPanel akan memberikan tampilan grafis dan automasi untuk memudahkan proses hosting di sebuah situs web. tools ini dapat berjalan dalam server/ hosting dengan sistem operasi centOS, Red Hat Linux, dan FreeBSD.Fungsi tools ini sebenarnya untuk mempermudah pengelolaan website, domain serta hosting itu sendiri.

\section{METODE PENELITIAN}

Metode yang digunakan dalam penelitian ini yaitu metode waterfall. Metode ini digunakan dengan mengikuti prosedur yang ada pada metode waterfall, yaitu dengan menganalisis, melihat spesifikasi, menentukan desain, memprogram, melalkukan tes pada web yang telah dibuat dan mengimplementasikan.

\subsection{Metode Pengumpulan Data}

Pada penelitian ini penulis mengambil data dengan metode sebagai berikut :

\section{Pengamatan}

Metode pengamatan ini digunakan untuk mengamati proses apa ygn dibutuhkan pada sistem informasi yang nantinya digunakan sebagai media sistem informasi teaching factory bakery yang ada di SMK Putra Anda Binjai.

2. Wawancara

Metode wawancara ini diperlukan untuk mendapatkan data lain secara langsung melalui wawancara. Wawancara dilakukan secara langsung kepada siswa, guru pembimbing teaching factory, kepala sekolah, wakil kepada sekolah bidang kurikulum dan konsumen yaitu siswa.

3. Studi Pustaka

Metode studi pustaka digunakan sebagai metode pengumpulan data yang di dapat dari beberapa jurnal yang berisi teori-teori yang berkaitan dengan penelitian yang akan dilakukan.

4. Dokumentasi

Metode ini digunakan untuk mendokumentasi segala bentuk kegiatan yang berkaitan dengan aktivitas teaching factory bakery SMK Putra Anda. Aktivitas diambil yaitu hasil produksi bakery yang dibuat oleh siswa siswi jurusan tata boga. 


\subsection{DFD (Data Flow Diagram)}

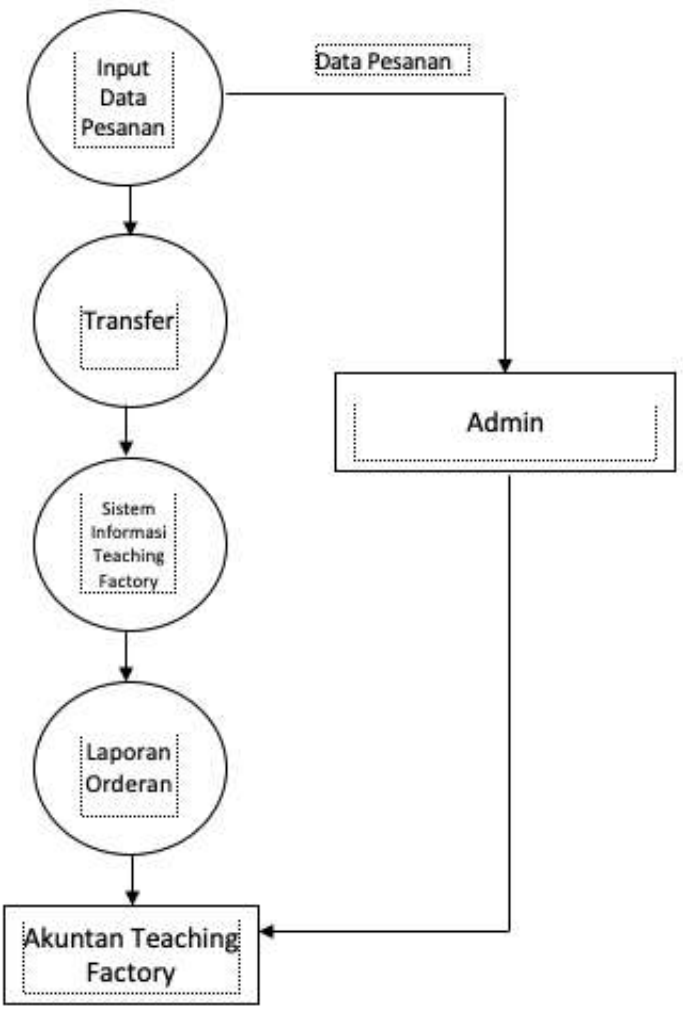

Gambar1.DFDTeaching Factory

Pada gambar 3.1 menjelaskan tentang alur kerja dari webteaching factory. Pembeli melakukan order di web hingga checkout dan mentransfer jumlah pembelian dan data akan masuk ke admin untuk bisa dilakukan pengiriman barang.

\section{HASIL DAN PEMBAHASAN}

Sistem informasi yang digunakan pada web ini sudah bisa melakukan order langsung, sehingga pembeli dapat dengan mudah melakukan proses jual beli. Pembeli juga dapat memilih menu yang di inginkan sesuai selera. Hasil dari pembelian nantinya pembeli akan mendapatkan bukti order langsung dari sistem secara otomatis.

\subsection{Tampilan Menu Utama}

Pada tampilan menu utama terdapat beberapa pilihan menu yang bisa di klik dan terdapat banyak pilihan makanan yang tersedia dalam masing-masing menu. Menu ini tentu nantinya bisa dirubah sesuai perubahan yang terjadi sewaktu-waktu. Pada tampilan ini juga terdapat kegiatan-kegiatan yang dilakukan teaching facktory bakery yang sengaja di publish agar orang yang mengunjungi web ini melihat bahwa teaching factory ini dilakukan dengan baik dan profesional. Pada tampilan ini nantinya akan menampilkan foto-foto terbaru yang nantinya akan dikelola oleh admin.
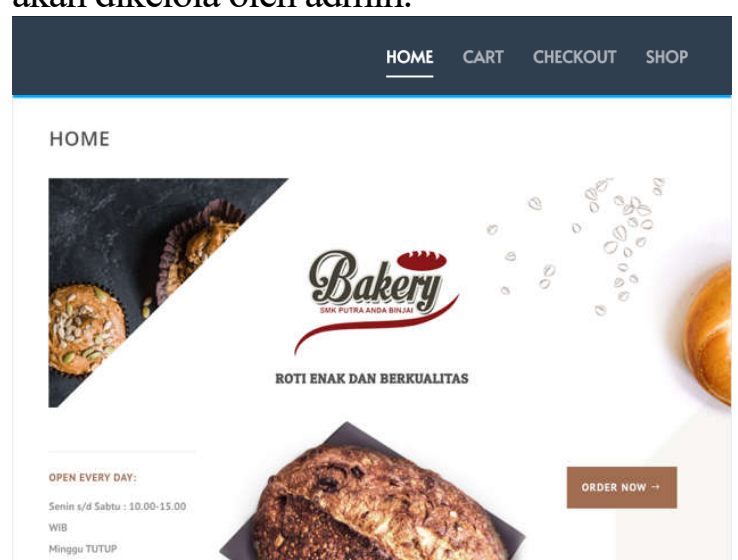

Gambar 2. Tampilan Menu Utama

\subsection{Menu Pilihan Makanan}

Pada menu ini, pelanggan bisa melihat dan memilih pilihan bakery yang tersedia. Ada banyak pilihan bakery yang tersedia dalam website, sehingga membuat website lebih berwarna.

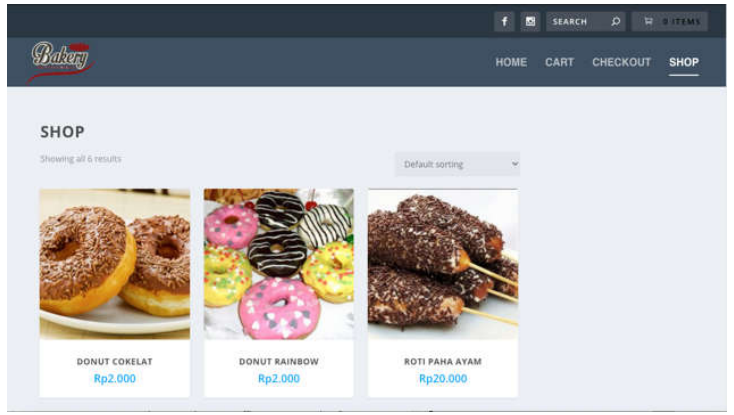

Gambar 3. Tampilan Menu Utama

\subsection{Tampilan CheckOut Order}

Pada halaman ini, pembeli bisa melakukan order secara langsung di web ini. Nantinya pembeli akan dipandu dengan isian 
form yang harus di isi sesuai dengan data pribadi.

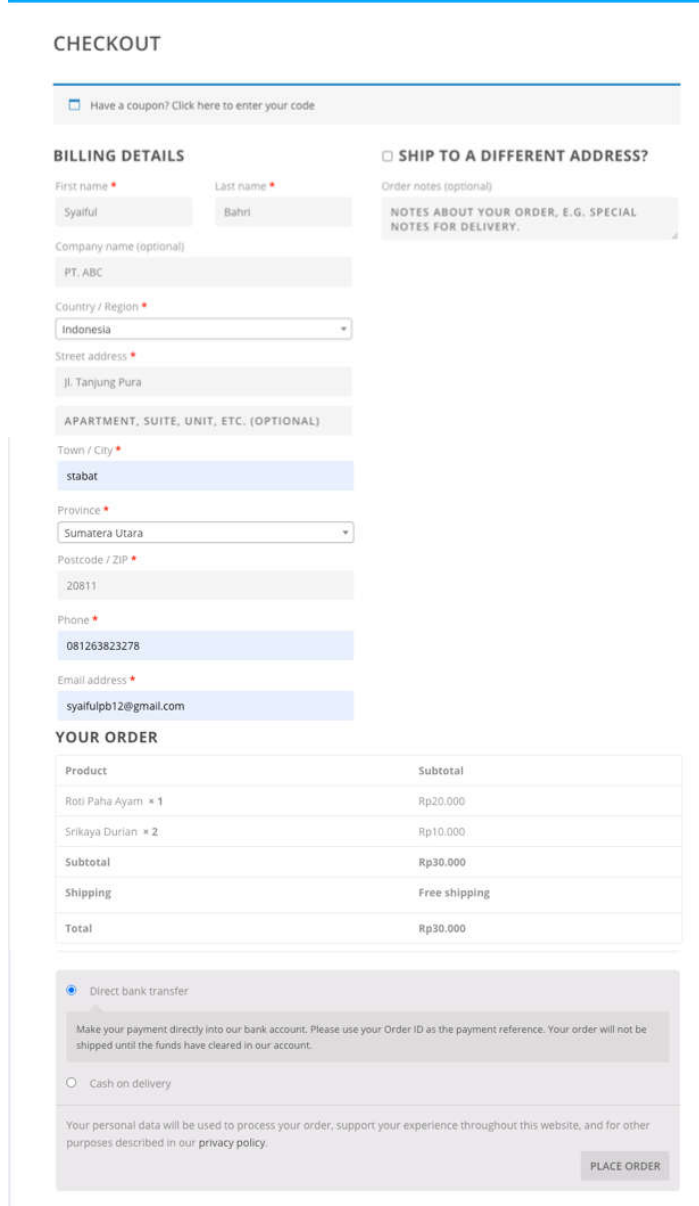

Gambar 4. Checkout Barang

\subsection{BuktiOrder}

Pada halaman ini pembeli yang sudah melakukan checkout akan menerima bukti pembelian barang melalui web secara otomatis. Selanjutnya pembeli akan mentransfer sejumlah uang sesuai besarnya biaya belanjaan.

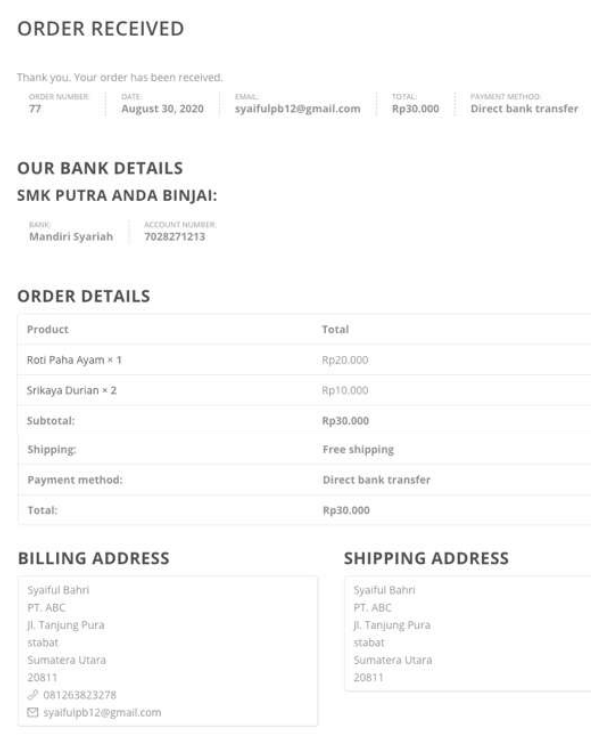

Gambar 5. Bukti Order

\section{KESIMPULAN DAN SARAN}

5.1 Kesimpulan

Kesimpulan dari penelitian sistem informasi ini yaitu :

1. Dengan adanya media promosi berbasis web sangat membantu tim teaching factory SMK Putra Anda dalam mempromosikan hasil produksi mereka dan semakin banyak dikenal orang.

2. Tampilan website yang mudah digunakan menjadi salah satu daya tarik pembeli mau mengunjungi situs tersebut.

3. Pembuatan sistem informasi berbasis web memudahkan dalam mengatur tampilan maupun perawatan, sehingga jika terjadi kendala atau kerusakan pada website, maka web bisa diperbaik dari jarak jauh tanpa harus datang ke lokasi sekolah.

\subsection{Saran}

Dalam penelitian ini tentu masih banyak kekurangan yang harus diperbaiki lagi, sehingga peneliti memberi saran kepada SMK Putra Anda yaitu :

1. Diharapkan ada adanya pengembangan pada sistem informasi 
berbasis web ini, karena jika website monoton, maka pengunjung juga akan bisa berkurang.

2. Diharapakan kedepannya untuk mengembangkan sistem keamanan dalam bertransaksi dengan website ini.

3. Disarankan agar adanya admin yang mampu melakukan backup agar jika terjadi kerusakan pada website, file masih tersimpan

\section{DAFTAR PUSTAKA}

[1] Buana, I Komang Setia, 2014. Jago pemrograman PHP. Dunia Komputer.

[2] F. Kamran and N. faisall Kharie, "Sistem Informasi Akademik Berbasis Web Pada Politeknik Sains Dan Teknologi Wiratama Maluku Utara," Indones. J. Inf. Syst. Sist., vol. 1, no. September 2016, pp. 39-46,2016.

[3] N. A. Rahmawati and A. C. Bachtiar, "Analisis dan perancangan sistem informasi perpustakaan sekolah berdasarkan kebutuhan sistem," Berk. Ilmu Perpust. dan Inf., vol. 14, no. 1, p. 76,2018.

[4] Supardi. 2013. Aplikasi Statistika dalam Penelitian Konsep Statistika yang Lebih Komprehensif. Jakarta: Change Publication.

[5] S. R. S. Siregar and P. Sundari, "Rancangan Sistem Informasi Pengelolaan Data Kependudukan Desa ( Studi Kasus di Kantor Desa Sangiang Kecamatan Sepatan Timur )," Sisfotek Glob., vol. 6, no. 1, pp. 76-82,2016.

[6] Yusri, "Sistem Informasi
Perpustakaan Berbasis Web Pada SMP Frater Makassar," J. Sist. Inf. Bisnis, vol. XIV, no. 2, pp. 66-77,2015. 